\title{
Potencialidad Celular Evolutiva y Medicina Regenerativa
}

\author{
Potential Evolutionary Cell and Regenerative Medicine
}

\author{
"Mariana Rojas \& **Manuel Meruane
}

ROJAS, M. \& MERUANE, M. Potencialidad celular evolutiva y medicina regenerativa. Int. J. Morphol., 30(4):1243-1251, 2012.

RESUMEN: Las células derivadas del embrioblasto o macizo celular interno (MCI) del blastocisto corresponden a las células madres embrionarias, ellas son pluripotentes, debido a que tienen la capacidad de generar todas las estirpes celulares y al resto, se les conoce como células madres adultas porque tienen un potencial de diferenciación mucho más restringido. Dentro de las células adultas podemos reconocer las células madre hematopoyéticas de la médula ósea y las células madres mesenquimales presentes en casi todos los tejidos conectivos adultos y destinadas a regenerar y reparar tejidos. Se las ha descrito formando parte de la médula ósea, en el mesénquima del cordón umbilical, en el tejido adiposo y en el tejido nervioso. La obtención y utilización de células madres de tejidos embrionarios y adultos es el tema de interés actual, en una nueva área de la medicina que pretende regenerar órganos y funciones. En esta revisión se analizan los aspectos más interesantes de la obtención de células madres, con sus respectivas proyecciones en medicina humana y veterinaria.

PALABRAS CLAVE: Células pluripotenciales; Células multipotenciales.

\section{INTRODUCCCIÓN}

El cigoto da origen a todas las células embrionarias y extraembrionarias. A medida que se avanza en la ontogenia celular, las células van perdiendo la potencialidad de dar origen a toda la gama de tipos celulares posibles. De totipotenciales, pasan a ser pluripotenciales, luego multipotenciales, hasta perder toda potencialidad de ser algo distinto a ella. Si los programas celulares son combinatorias de expresión o represión estable de genes, se puede plantear que una célula pluripotencial expresa más genes que una célula terminalmente diferenciada, sin potencial. En un modelo de diferenciación in vitro, se ha visto que en el paso de una célula troncal embrionaria a una célula progenitora de neuronas, la relación entre silenciamiento de genes versus la activación es de 23:1, es decir, para que una célula adquiera un compromiso de linaje es mucho más voluminosa la represión que la activación de genes. Por el contrario, la reprogramación celular se ha definido como la readquisición de potencialidad de diferenciación y por lo tanto la reactivación de programas genéticos.

Las células conservan la información genética capaz de llevar adelante el desarrollo de un organismo completo. En otras palabras la información genética no se pierde, se expresa y luego se silencia o viceversa, su expresión puede estar reprimida y en algún momento de la ontogenia celular se comienza a expresar. La selección de los genes que se expresan o se silencian en una célula determinada es el "programa celular". Este programa debe ser lo suficientemente estable como para ser transmitido a través de la mitosis, permitiendo que las distintas células del organismo adquieran compromisos de linaje durante el desarrollo embrionario y se vayan diferenciando en las células que conforman los distintos tejidos y órganos. Sí se reprograman las células a un estado pluripotencial y se le dan las señales adecuadas para que se rediferencien en el tipo celular de interés, se podría obtener el sustrato para regenerar la función de distintos órganos que han fallado (Muñoz \& Concha, 2011).

Las células totipotentes. Se dice que el huevo fecundado es totipotente porque tiene la capacidad de generar un individuo completo junto a sus anexos embrionarios, esta totipotencialidad se mantiene durante las primeras divisiones de segmentación (Fig.1). Las blastómeras pierden su totipotencialidad en el momento de la primera diferenciación después de completar 8 blastómeras y se inicia un proceso llamado compactación. Durante este proceso se forman medios de unión entre las blastómeras externas, determinando la constitución de dos poblaciones celulares diferentes. La población externa formará la pared del blastocisto. En cambio, las células que quedan ubicadas internamente

\footnotetext{
* Laboratorio de Embriología Comparada, Facultad de Medicina, ICBM. Universidad de Chile.

***Programa de Magíster en Ciencias Biomédicas mención Morfología, Facultad de Medicina, Universidad de Chile.
} 


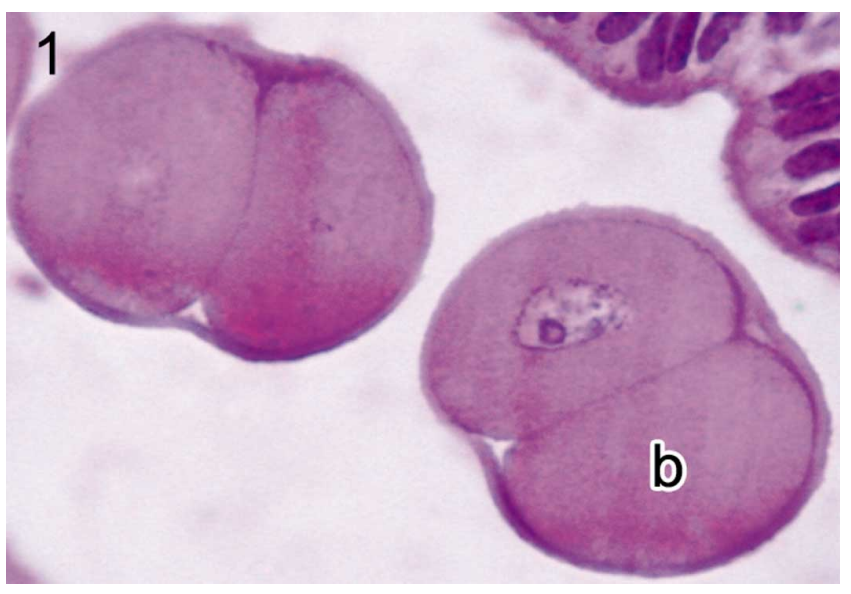

Fig. 1 Embriones de ratón, formados por blastómeras totipotentes (b).

originarán al embrioblasto llamado también macizo celular interno (MCI). Poco tiempo después se forma una cavidad central formando el blastocisto (Fig. 2), el MCI está constituído por células pluripotenciales que originarán las tres hojas embrionarias del embrión, el amnios, saco vitelino y alantoides. El trofoblasto, en cambio, formará el corion y la placenta.

La totipotencialidad, permite en medicina veterinaria, generar gemelos a partir de la separación de las primeras blastómeras de un animal de alta calidad genética (Figs. 1 y 3). El resultado es que probablemente van a nacer dos o tres crías de excelente calidad genética a partir de un solo embrión. Este método de dividir embriones ha sido utilizado por diversas industrias desde 1986, con el objeto de hacer proliferar un ganado de condiciones genéticas excepcionales. En este caso la constitución genética de las crías es diferente a la de los padres pero es exactamente igual entre ellas. (Por definición, dos o más individuos son clónicos cuando su constitución genética es exactamente igual).

Las células madres pluripotenciales. Se denomina célula madre o troncal a una célula indiferenciada capaz de autoreplicarse por largos períodos de tiempo y diferenciarse en un amplio rango de células especializadas dependiendo del medio que la rodea (citoquinas, factores de crecimiento, etc) y su consecuente alteración de la expresión génica.

Pluripotente: Puede diferenciarse en cualquier tipo de célula de las tres hojas embrionarias, pero no pueden generar un individuo completo, corresponden a las células madres obtenidas del embrioblasto (masa celular interna) del blastocisto (Fig. 2).

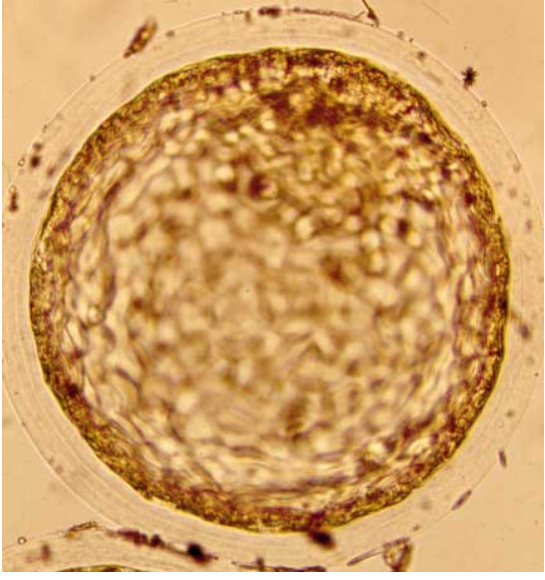

Fig. 2. Blastocisto de conejo constituído por macizo celular interno con sus células pluripotenciales y trofoblasto.

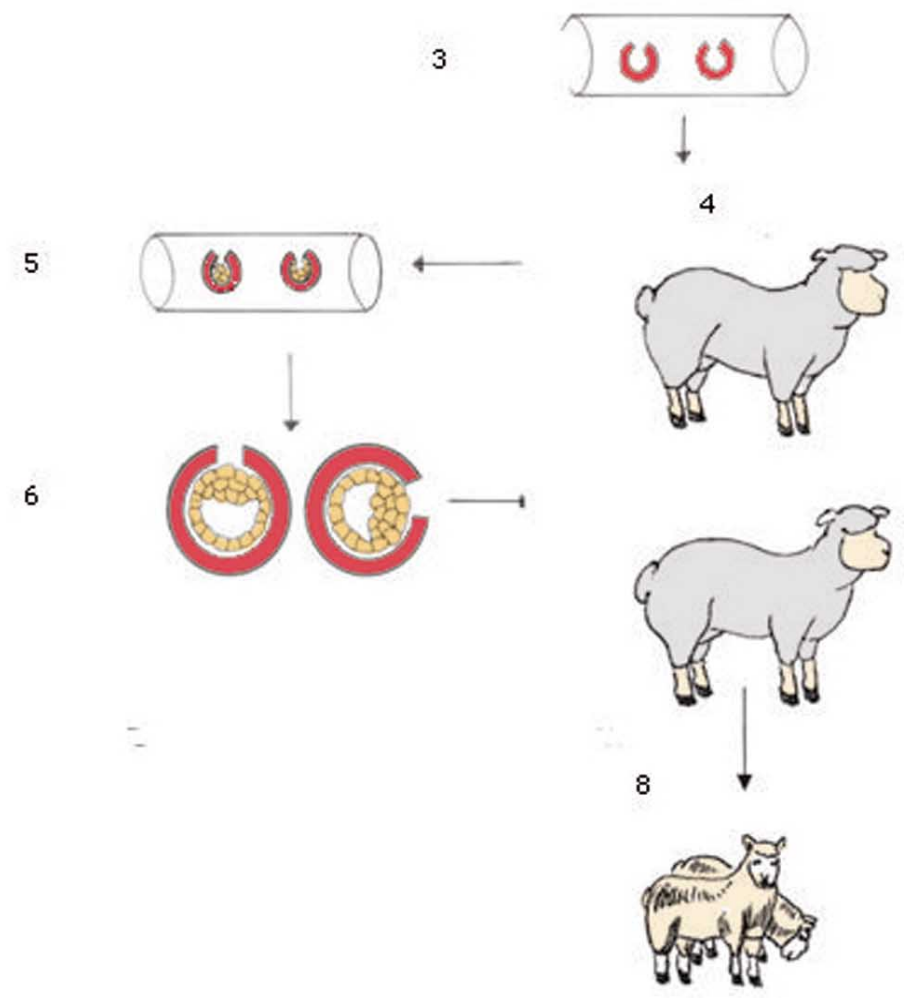

Fig. 3. En un embrión formado por dos blastómeras (1) se separan las dos células, colocando a cada una de ellas en una zona pelúcida diferente (2), luego se ubican en cilindros de agar para proteger (3), y se transfieren a una oveja pseudopreñada (4). Después de unos días se sacan estos cilindros para observar su desarrollo ( 5 y 6 ) y se transfieren a una hembra receptora definitiva (7). Al cabo de cinco meses nacen gemelos idénticos (8). 


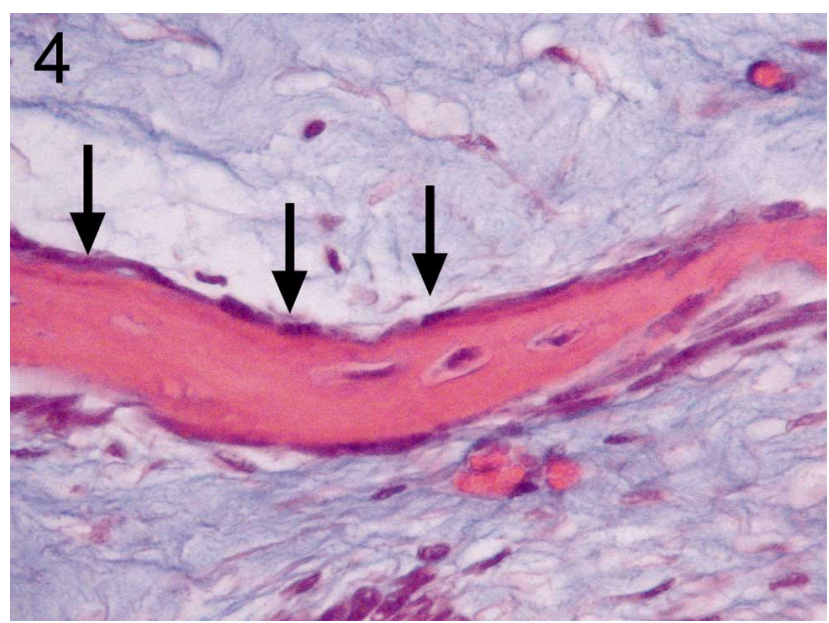

Fig. 4 Células osteógenas multipotenciales en cabeza de feto de oveja, H-E Azul de Alcián 400X.

Multipotente: Sólo pueden diferenciar células de la misma hoja embrionaria. La mayor parte de las células encontradas en los tejidos adultos corresponde a este tipo. Un ejemplo son las células osteoprogenitoras que se pueden diferenciar en células adiposas, cartilaginosas u óseas (Fig. 4).

Unipotentes: Poseen la habilidad de autorrenovación pero sólo se pueden diferenciar en un linaje, por ejemplo la células epidérmicas basales (Fig. 5).

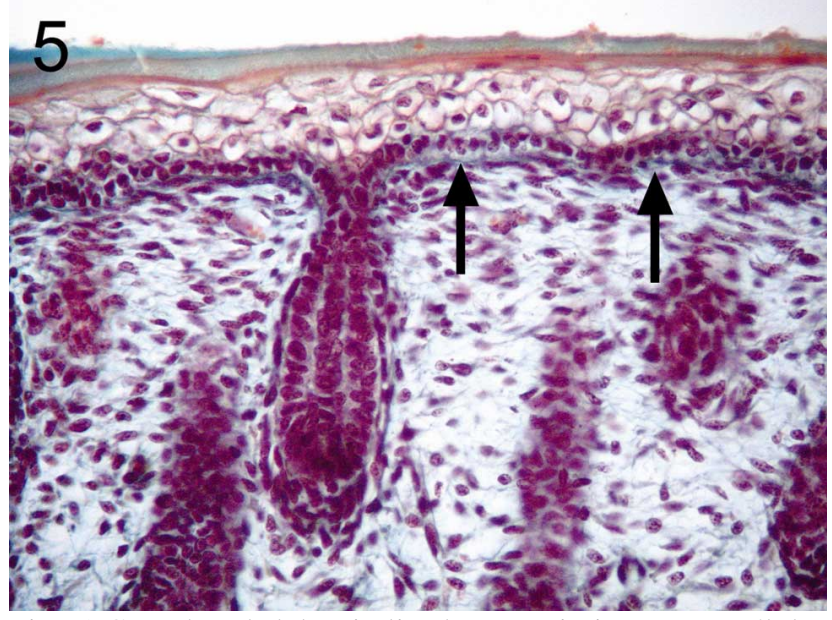

Fig. 5 Capa basal del epitelio de revestimiento con células unipotenciales. Piel de feto de oveja, tricrómico de Masson, 400X.

Si bien las células madres pueden obtenerse a partir de casi todos los tejidos de un individuo y a cualquier edad, con el tiempo se va restringiendo el potencial de diferenciación. Inicialmente un oocito fecundado es totipotente, un blastocisto es pluripotente, luego podemos obtener células desde el cordón umbilical y a partir de tejidos adultos como la médula ósea y tejido adiposo pero éstas son multipotentes, cada vez con capacidad de proliferación y diferenciación más limitada (Fig. 6).

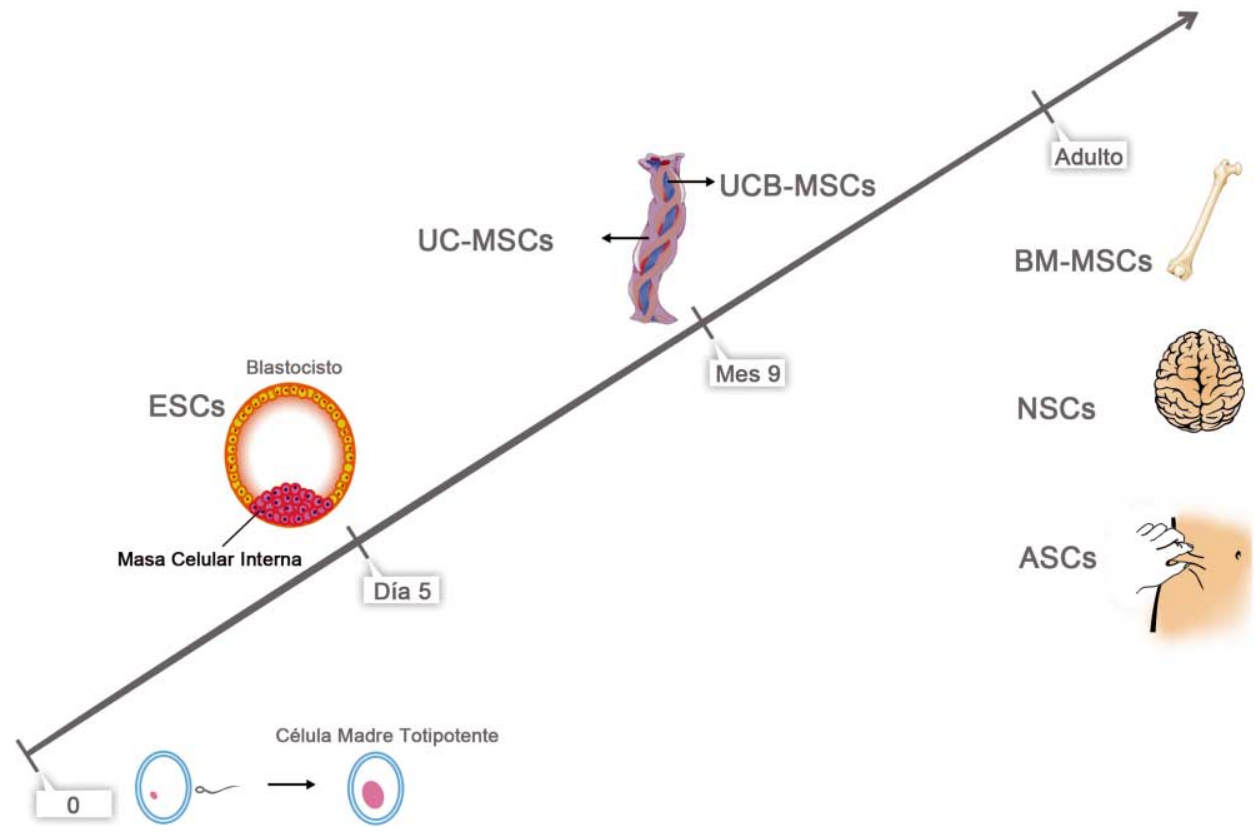

Fig. 6. Se muestra a lo largo de la vida de un individuo las diferentes opciones para la obtención de células madres. El oocito fecundado es una fuente de células totipotentes, las células del macizo celular interno (embrioblasto) del blastocisto son las llamadas células madres embrionarias (ESCs), las células de la sangre del cordón umbilical (UCB) son consideradas células madres adultas jóvenes y el resto obtenidas de otros tejidos son células madres adultas propiamente tal. Células troncales mesenquimales derivadas de la médula ósea (BM-MSCs). NSCs, células troncales neurales. ASCs, células troncales derivadas de células adiposas. 
A las células derivadas del blastocisto las denominaremos células madres embrionarias (Embryonic Stem Cells, ESCs) y al resto, células madres adultas. Dentro de las células adultas las que forman parte del mesénquima de los tejidos y no forman elementos hematopoyéticos, las denominaremos Células Madres Mesenquimales (Mesenchymal stem cells, MSCs) (Fig. 6).

Células madres embrionarias. Las células madres obtenidas de embriones en la etapa de blastocisto (ESCs) tienen la capacidad para formar todas las células del cuerpo, porque mantienen un cariotipo normal, y una telomerasa altamente activa, además logran en el cultivo, un notable potencial de proliferación durante un largo período de tiempo, dando la posibilidad de una expansión ilimitada.

Las ESCs se obtienen del MCI (embrioblasto) del blastocisto y deben cultivarse in vitro para obtener líneas de células pluripotenciales. Estas células madre pueden seguir una de dos rutas: a) mantenerse en un estado indiferenciado, o bien b) diferenciarse en líneas celulares más específicas, por ejemplo cardíacas, neurales, sanguíneas, etc., dependiendo del medio de cultivo que se utilice.

Aún cuando la mayoría de los estudios se han realizado en animales, en 1998 dos laboratorios informaron que habían obtenido células madres de embriones humanos. En estos casos, las células madres fueron obtenidas a partir de células germinales primordiales derivadas de fetos abortados espontáneamente. En ambos casos las células embrionarias fueron pluripotentes, y capaces de proliferar y diferenciarse en el cultivo y también de formar otras células madres que producían neuronas y sangre (Geahart, 1998; Thomson et al., 1998; Gilbert, 2005). En nuestro laboratorio hemos obtenido células pluripotenciales a partir de células germinales primordiales de embriones de conejo (Rojas et al., 2001).

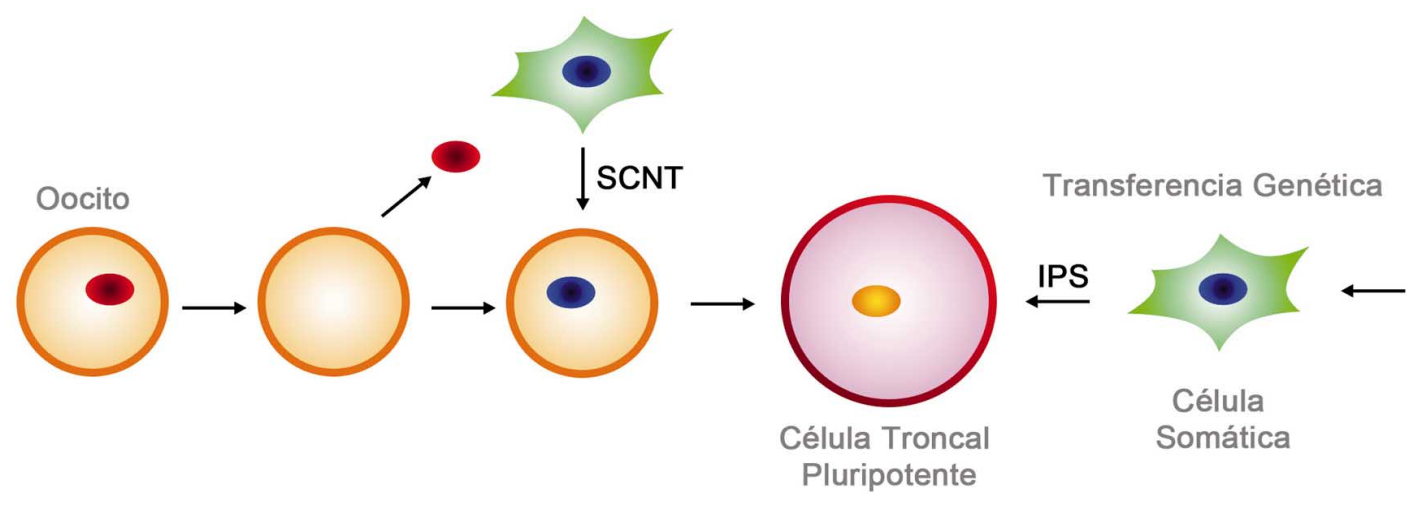

Debido a que estas células pueden proliferar indefinidamente en un medio de cultivo y luego diferenciarse en múltiples tipos celulares, las células humanas potencialmente pueden proveer de un aporte ilimitado de tejidos para trasplantes humanos. La terapia de transplante basado en estas células, es una promesa de tratamiento exitoso para una variedad de enfermedades como Parkinson, diabetes, alteraciones cardíacas, alteraciones degenerativas del cerebro o lesiones de la medula espinal, y también para producir nuevas células sanguíneas en personas con anemia; sin embargo aun hay barreras que superar para un tratamiento clínico exitoso, principalmente debido a la presencia de anormalidades cariotípicas en algunos cultivos y a la eventual producción de teratomas (Mitalipova et al., 2005; Leeb et al., 2010).

También se ha desarrollado la idea de clonar un embrión temprano a partir de las células somáticas del paciente y así generar sus propias células madre. French et al. (2008) obtuvieron un blastocisto humano posterior a la transferencia nuclear de un fibroblasto en un oocito, esto se denomina transferencia nuclear celular somática (Somatic Cell Nuclear Transfer, SCNT). El resultado es un grupo de células pluripotentes idénticas genéticamente al dador de fibroblastos, el procedimiento se conoce también como clonación terapéutica (Fig. 7). Las desventajas de esta técnica es que son muy laboriosas e intensivas, dañinas para la célula y muy ineficientes; además se requiere una gran cantidad de oocitos. Sin embargo, esta técnica podría ser utilizada en animales con riesgo de extinción. Existen bancos de fibroblastos obtenidos de la oreja de animales vulnerables y en riesgo de extinción congelados en nitrógeno líquido, los cuáles pueden ser introducidos en ovocitos recuperados provenientes de ovarios de vacas. Después de las 22 horas de cultivo de los ovocitos se retira el polocito mediante un micromanipulador (Fig. 8). Luego se realiza la microinyección de los núcleos de fibroblastos en el espacio

Fig. 7. Se muestran dos maneras para obtener células madres pluripotentes a partir de células somáticas. A la izquierda el procedimiento de transferencia celular nuclear somática (Somatic cell nuclear transfer, SCNT) y a la derecha el procedimiento de inducción por transfección viral (induced Pluripotent Stem Cell, iPSC) 

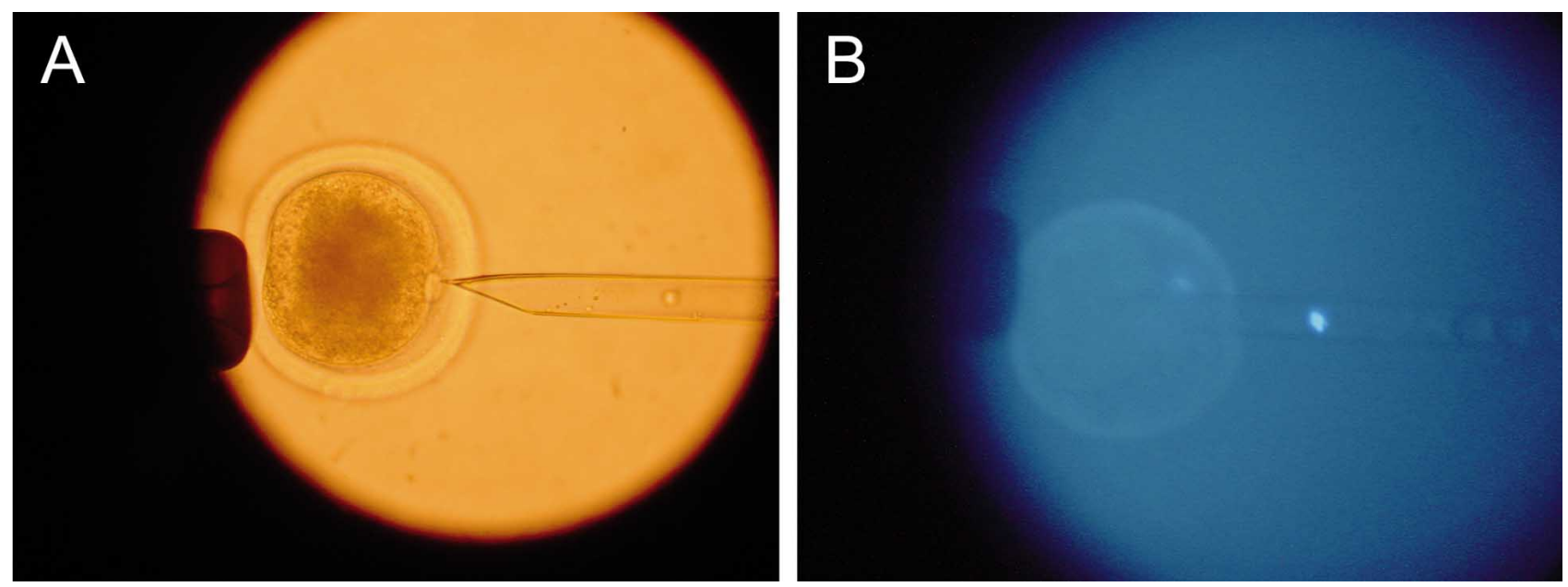

Fig. 8 (A) Transferencia nuclear somática modificada. Desde los ovocitos se retira el polocito mediante un micromanipulador. (B) El corpúsculo polar y la placa metafásica se ven brillantes (Proyecto ECOS-CONICYT Rojas, M.; Guillomot, M. \& Venegas, F.).

perivitelino de los ovocitos. La fusión de membranas celulares es obtenida por choques eléctricos. Los embriones así reconstituidos son cultivados en presencia de células nutricias durante 7 días (Rojas et al., 2005; 2006).

Reprogramación celular. Se define la reprogramación celular como la adquisición de características de célula troncal embrionaria. Estas células se definen por dos capacidades esenciales: la pluripotencialidad, que es la capacidad de diferenciarse en distintos tipos celulares. La otra característica es la capacidad de autorrenovarse. Esto se logra mediante una división mitótica asimétrica, conservando una de las células hijas las características de su madre, es decir sigue siendo célula troncal, y la otra adquiere nuevas características que la van diferenciando hacia un cierto linaje celular. La primera se mantiene siempre en el ciclo celular con una capacidad de generar una progenie en forma indefinida, la segunda en algún momento de su ontogenia pasa a G0. Utilizando estos criterios de reprogramación se pudo reproducir los resultados de la transferencia nuclear mediante técnicas que se fueron desarrollando sucesivamente a medida que los avances de la biología molecular lo permitieron (Muñoz \& Concha, 2011).

Un avance en la reprogramación celular es la creación de células madres pluripotentes inducidas (induced Pluripotent Stem Cells, iPSCs), publicada en el año 2006 por Takahashi \& Yamanaka. Estas células se generan mediante la reprogramación de células somáticas por la introducción de factores de transcripción a través de retrovirus. (Fig. 7) Los genes introducidos son el Oct4, Sox 2 y c-Myc con Klf4 o Nanog con Lin28. Los dos primeros son factores de transcripción específicos de células troncales asociados a pluripotencialidad. Los dos últimos son factores de trans-

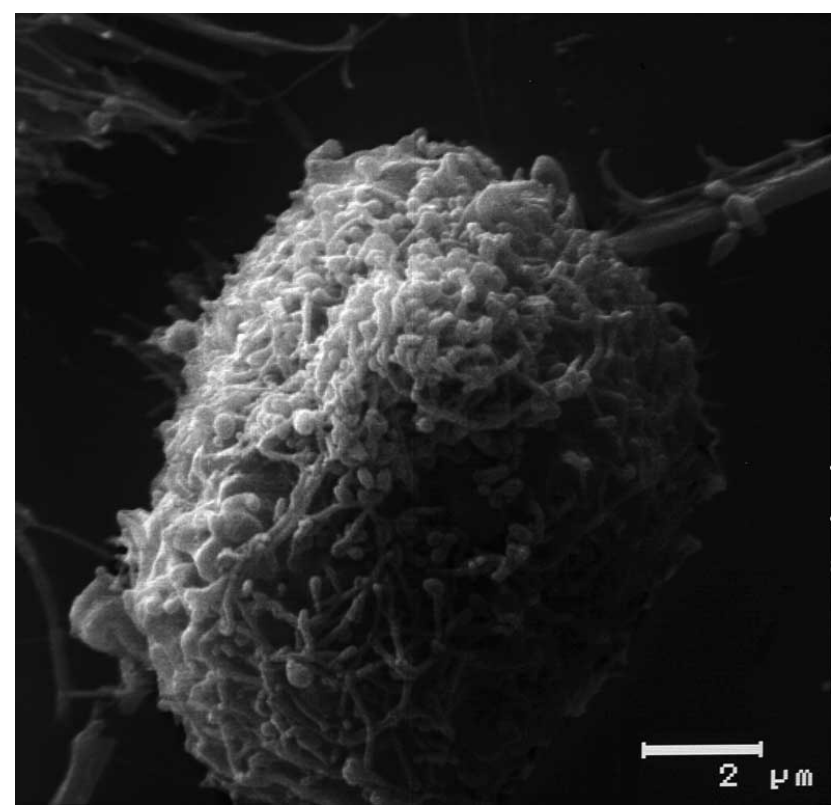

Fig. 9. Microscopía Electrónica de Barrido (SEM) de una célula troncal derivada del tejido adiposo (ASC) iniciando su crecimiento. Carece de filopodios. Aumento 7000x.

cripción oncogénicos u oncogenes. De estos genes el Oct4 resulta ser el más importante, el cual no puede ser sustituido. Las características son similares a las ESCs en cuanto a la morfología, marcadores de superficie y actividad de telomerasa. Uno de los principales problemas en su utilización es la baja eficiencia de reprogramación que va del 0,1 al 0,001\% de éxito, también pueden generar teratomas y activar oncogenes. Al igual que las ESCs se han realizado múltiples ensayos en animales pero no se ha autorizado su uso terapeútico en humanos. 
Células madres adultas. Los tejidos ya especializados están compuestos principalmente de células ya restringidas en su potencial de diferenciación, pero en su evolución los organismos han incorporado también células madres somáticas adultas en los tejidos con el fin de renovar y reparar en condiciones fisiológicas y patológicas.

Células madres de la médula ósea: Durante varios años se consideró la célula madre hematopoyética como la única célula en la médula ósea con capacidad generativa y se pensaba que sólo era multipotencial. Sin embargo hoy se sabe que la composición de la médula ósea es más compleja, pues en ella se han identificado un grupo heterogéneo de células madres adultas compuesto por las células hematopoyéticas (hematopoietic stem cells, HSC), población lateral, células progenitoras adultas multipotentes (MAPC) y las células mesenquimales (Mesenchymal stem cells, MSCs).

Las células madres hematopoyéticas se han utilizado desde hace más de 50 años en el transplante de médula ósea y han demostrado su efectividad en el tratamiento de diversas enfermedades como leucemias y mielomas. En humanos el fenotipo de superficie es lin- CD34+ CD38+ CD133+ c-Kit/ CD117+ CD59+ Thy1/CD90+ CXCR4+ y se diferencian clásicamente en linajes mieloides y linfoides.

Las células madres mesenquimáticas derivadas de la médula ósea (BM-MSCs) son otro tipo de célula adulta multipotente capaz de diferenciarse en todos los linajes mesodérmicos y son similares a las aisladas en otros órganos (Koerner et al, 2006). Si bien han sido descritas en la última década (Bianco et al., 2001), se atribuye a Friedentein et al., (1974) su descubrimiento al describir estas células como precursores de fibroblastos presentes en la médula ósea. En felinos se han aislado y caracterizado (Martin et al., 2002). Su potencialidad y características serán descritas en conjunto con el resto de las MSCs, lo mismo se ha realizado en equino (Smith et al., 2003; Baghaban et al., 2009; Berg et al., 2009).

Células madres del cordón umbilical: Otra fuente de células madres es la sangre que fluye por el cordón umbilical, En un $\mathrm{ml}$ de sangre del cordón umbilical hay aproximadamente 8000 progenitores de eritrocitos, entre 13 y 24 mil progenitores mieloides, y entre 1000 y 10.000 células madres pluripotenciales. Se las considera células madres adultas "jóvenes", dentro de sus ventajas destaca que tienen telómeros más largos, alto potencial de proliferación, reducción del riesgo de contaminación viral y mejor tolerancia al antígeno de histocompatibilidad HLA (Gilmore et al., 2000). Los marcadores de superficie más frecuentes incluyen el CD7 CD34 CD38 CD90 y CD133 (McGuckin et al., 2003). Esta forma de obtención de células madres estaría mucho más de acuerdo con diversas regulaciones éticas. En octubre de 19 se realizó el primer transplante de células madres de sangre del cordón umbilical (Umbilical Cord Blood Stem Cells UCB-SCs) a la médula ósea, a pesar del escepticismo de científicos y clínicos, desde entonces se han convertido en una fuente común para transplante alogénico. A la fecha se estima que 600.000 unidades de UCB han sido almacenadas en bancos y unas 20.000 unidades han sido utilizadas para transplantes en adultos y niños con enfermedades malignas y no malignas con buenos resultados (Wagner \& Gluckman, 2010). Actualmente hay varios bancos para almacenar UCB, y muchos padres tienes la opción de congelar un UCB de sus hijos y mantenerlos allí hasta el momento en que ellos pudieran necesitar algún trasplante de células. En relación a los animales Koch $e t$ al. (2007), informaron por primera vez, el aislamiento de células madre mesenquimales del cordón umbilical de equinos y su diferenciación en osteocitos, condrocitos y adipocitos.

Células madres de otros tejidos adultos: Denominaremos célula madre mesenquimal (MSC) a un tipo de célula madre adulta presente en casi todos los tejidos conectivos adultos principalmente de origen mesodérmico destinada a regenerar y reparar (Young et al., 2002). Se las ha descrito formando parte de la médula ósea (BM-MSCs), en el tejido mesenquimal del cordón umbilical, en el tejido adiposo (Zuk et al., 2001) (Adipose Derived Stem Cells, ASCs) y en el tejido nervioso.

Un hecho importante es el carácter de "inmunoprivilegiadas" de la mayoría de las MSCs, al carecer de HLA II, además tienen la habilidad de suprimir la reacción linfocítica mixta, en consecuencia se las puede injertar en forma alogénica (Puissant et al., 2005; Uccelli et al., 2007).

Dentro de las propiedades funcionales de las ASCs y BM-MSCs está la capacidad de secreción de potentes factores de crecimiento como el factor de crecimiento vascular endotelial (VEGF), factor de crecimiento hepatocítico (HGF) y factor de crecimiento símil a la insulina, especialmente en respuesta a la hipoxia (Rehman et al., 2004; Wang et al., 2006).

La utilización de MSCs con fines regenerativos y en enfermedades inmunológicas va en aumento, ante lo cual es necesario citar los criterios de Gimble et al. (2007), quien sugiere que cualidades debe tener una célula troncal para se utilizadas con fines médicos, estas son:

1. Presencia en cantidades muy abundantes (millones a billones de células)

2. Aislables con procedimientos mínimamente invasivos.

3. Diferenciables en múltiples linajes celulares de manera regulable y reproducible.

4. Transplantables en forma autóloga o alogénica.

5. Manipulables de acuerdo a las actuales Guías de Buena Práctica. 
Se ha avanzado considerablemente en el tratamiento de lesiones ortopédicas de equinos tales como desgarros de tendón, fracturas y degeneración de cartílago, gracias a la técnica de las células madres derivadas del tejido adiposo (ASCs). Harman et al. (2006). Estos avances se deben a que estos animales tienen mucho valor y se pueden ver gravemente discapacitados con estas lesiones. En un estudio con 170 caballos de carrera de obstáculos, se encontró que casi un $80 \%$ de ellos podría volver a las carreras, en comparación con el $30 \%$ que lo hacían con las terapias tradicionales. Después de tres años, la tasa de repetición de la lesión era mucho más baja en los animales tratados con células madre alrededor de un 23\%, en comparación con los datos ya publicados y que reflejaban un $56 \%$. (Herther, 2001)

Al hablar de lesiones ortopédicas tales como desgarros de tendón, fracturas y degeneración de cartílago, existen mayores adelantos para aplicar en equinos y caninos que en humano. Esto se debe a que la medicina veterinaria posee regulaciones menos severas a la hora de tratar a los animales con terapias experimentales. Aunque las células madre embrionarias tienen mayor potencialidad de diferenciación, tienen algunas desventajas asociadas porque proceden de otro animal, por lo tanto se consideran material extraño y el cuerpo puede rechazarlas. Las células madre adultas, en cambio, tienen la ventaja de que son fáciles de obtener, y como vienen del mismo animal, no hay ninguna posibilidad

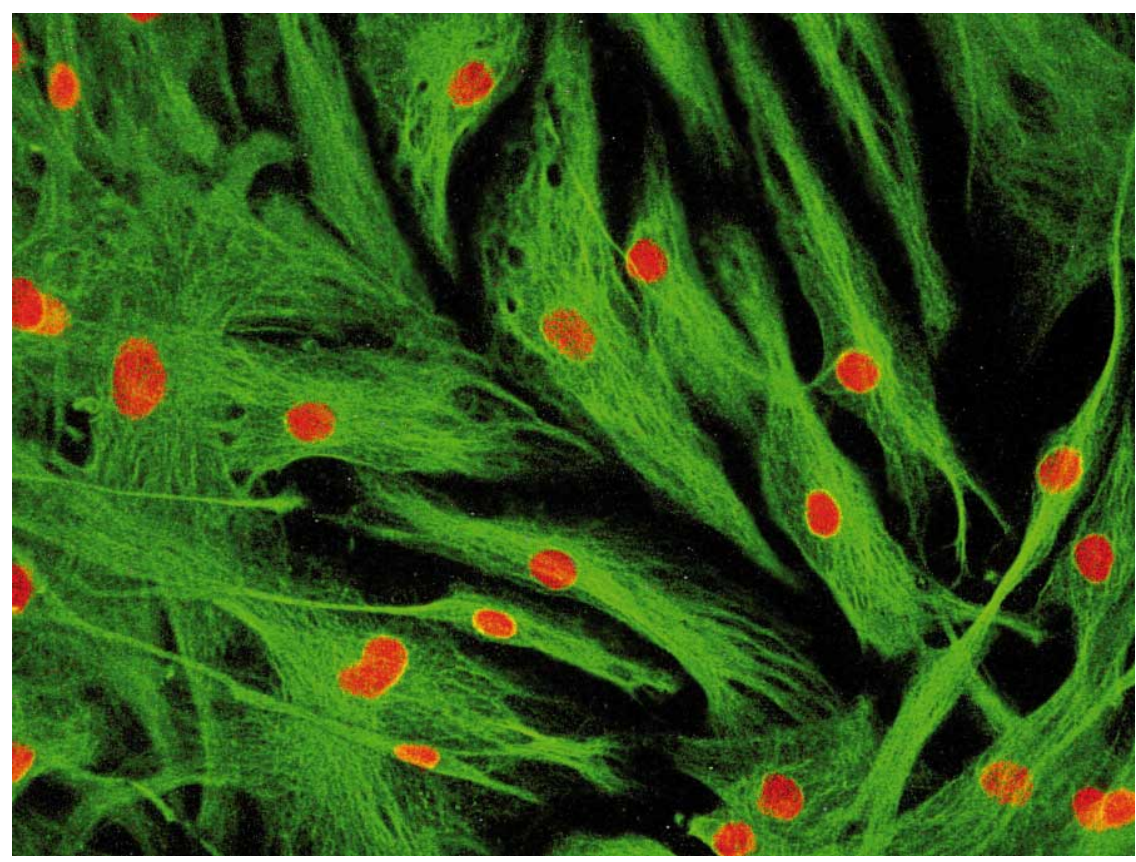

Fig. 10. Cultivo de células troncales derivadas del tejido adiposo (ASCs) teñidas con técnica de inmunofluorescencia de doble marcaje: Los núcleos se observan con Propidio y los filamentos intermedios con anticuerpo antivimentina-FITC. Aumento 20x. $72 \mathrm{hrs}$ de crecimiento. de rechazo. Con una sola inyección de células troncales derivadas del tejido adiposo, algunos perros con claudicación muestran una mejoría durante varios meses a más de un año. Por otra parte, la tasa de crecimiento in vitro, y potencial de diferenciación osteogénica y adipogénica de ASC equina muestran algunas diferencias a los documentados para ASCs en otras especies de mamíferos, sin embargo, se ha confirmado que el tejido adiposo es una fuente potencial de células madre adultas para aplicaciones de ingeniería de tejidos en medicina veterinaria (Vidal et al., 2007)

Mediante el uso de (ASCs) no es necesario realizar un cultivo tradicional, que generalmente toma una semana o más. Esto significa que una vez que el tejido adiposo se obtiene del paciente, el tiempo para poder tratarlo con sus propias células es 48 horas. Las células madre pueden aliviar la osteoartritis liberando factores tróficos, que estimulan las células de toda el área. También tienen propiedades anti-inflamatorias y pueden diferenciarse en otra célula para estimular la reparación de tejidos dañados. (Gimble \& Bunnell, 2007). (Vidal et al., 2007).

El proceso que está involucrado con el uso de estas células para tratar la artritis en los perros es relativamente simple. El primer paso es la recolección del tejido adiposo, este es un procedimiento quirúrgico estéril que requiere que el perro sea anestesiado. Las células adiposas se obtienen de la región inguinal, la región torácica, o la grasa falciforme, que es en el abdomen. Se requiere sólo $15 \mathrm{~g}$ de tejido adiposo. Luego se procesa el tejido en medios de cultivo en una incubadora y 48 horas después puede ser inyectado en las articulaciones afectadas. La inyección de las células se puede hacer con sólo sedación. Aunque las células se pueden inyectar en el torrente sanguíneo y tendrá un efecto en las articulaciones artríticas, se ha encontrado que es más eficaz si se inyecta directamente en las articulaciones afectadas. Los resultados toman alrededor de un mes para manifestarse plenamente y pueden durar varios meses a más de un año en algunos pacientes. Una serie de estudios en animales han demostrado que estas terapias con células madre son efectivas, permitiendo que cada vez más animales vuelvan a correr, reduciendo las tasas de repetición de lesiones, y acortando los tiempos de curación. 
En el laboratorio hemos logrado con éxito el aislamiento, cultivo y la caracterización de células troncales derivadas del tejido adiposo humano (ASCs) (Meruane \& Rojas, 2010) y tal como podemos observar en la figura 9 inicialmente tienen un aspecto redondeado y en la medida que pasan las horas dentro de la placa de cultivo toman un aspecto fibroblástico (Fig.10). Adicionalmente hemos desarrollado esta técnica de obtención celular en ratas, utilizado estas células troncales para mejorar la cicatrización en áreas de piel que tenían un sustituto dérmico con buenos resultados (Meruane et al., 2012).
En conclusión, las células embrionarias del blastocisto son las que tienen capacidad de generar todas las células del organismo, las otras células madres como las del cordón umbilical y la médula ósea del adulto tienen un potencial más restringido. Las expectativas que se han hecho respecto al potencial terapéutico de la micromanipulación embrionaria son enormes, sin embargo quedan dilemas éticos y científicos por resolver. Tal vez el uso de las MSCs y de las iPSCs puede obviar la necesidad de discutir estos problemas y es de esperar que en los próximos años tengamos estudios clínicos que demuestren su eficacia.

ROJAS, M. \& MERUANE, M. Potential evolutionary cell and regenerative medicine. Int. J. Morphol., 30(4):1243-1251, 2012.

SUMMARY: Embryoblast derived cells or inner cell mass (ICM) of blastocysts correspond to embryonic stem cells, are pluripotent them, because they have the capacity to generate all cell lines and the remainder are known as stem cells adults because they have the potential for much more restricted differentiation. Within cells can recognize adult hematopoietic stem cells and bone marrow mesenchymal stem cells present in nearly all connective tissues and intended adult tissue repair and regeneration. They have been described as part of the bone marrow, umbilical cord mesenchyme in adipose tissue and nerve tissue. The collection and use of embryonic stem cells and adult tissues is the subject of current interest in a new area of medicine that aims to regenerate organs and functions. In this paper, we analyze the most interesting aspects of obtaining stem cells, with their projections in human and veterinary medicine.

KEY WORDS: Stem Cells.

\section{REFERENCIAS BIBLIOGRÁFICAS}

Baghaban Eslaminejad, M. R.; Taghiyar, L.; Dehghan, M. M.; Falahi, F. \& Kazemi Mehrjerdi, H. Equine marrow-derived mesenchymal stem cells:isolation, differentiation and culture optimization. Iranian Journal of Veterinary Research, Shiraz University, 10(1):1-11, 2009.

Berg, L.; Koch, T. G.; Heerkens, T.; Bessonov, K.; Thomsen, P. \& Betts, D. Chondrogenic potential of mesenchymal stromal cells derived from equine bone marrow and umbilical cord blood. Vet. Comp. Orthop. Traumatol., 22:363-70. 2009.

Bianco, P.; Riminucci, M.; Gronthos, S. \& Robey, P. G. Bone marrow stromal stem cells: nature, biology and potential applications. Stem Cells, 19:180-92, 2001.

Black, L. L.; Gaynor, J.; Gahring, D.; Adams, C.; Aron, D.; Harman, S.; Gingerich, D. A. \& Harman, R. Effect of adipose-derived mesenchymal stem and regenerative cells on lameness in dogs with chronic osteoarthritis of the coxofemoral joints: A randomized, double-blinded, multicenter, controlled trial. Vet. Ther., 8(4):272-84, 2007.

Dominici, M.; Le Blanc, K.; Mueller, I.; Slaper-Cortenbach, I.; Marini, F.; Krause, D.; Deans, R.; Keating, A.; Prockop, Dj. \& Horwitz, E. Minimal criteria for defining multipotent mesenchymal stromal cells. The International Society for Cellular Therapy position statement. Cytotherapy, 8(4):315-7, 2006.

French, A. J.; Adams, C. A.; Anderson, L. S.; Kitchen, J. R.; Hughes, M. R. \& Wood, S. H. Development of human cloned blastocysts following somatic cell nuclear transfer with adult fibroblasts. Stem Cells, 26:485-93, 2008.
Friedenstein, A. J.; Deriglasova, U. F.; Kulagina, N. N.; Panasuk, A. F.; Rudakowa, S. F.; Luriá, E. A. \& Ruadkow, I. A. Precursors for fibroblasts in different populations of hematopoietic cells as detected by the in vitro colony assay method. Exp. Hematol., 2(2):83-92, 1974.

Geahart, J. New potential for human embryonic stem cells. Science, 282:1061-2, 1998.

Gilbert, S. F. Development Biology. Sunderland, MA, Sinauer Associates, 2005.

Gilmore, G. L.; DePasquale, D. K.; Lister, J. \& Shadduck, R. K. Ex vivo expansion of human umbilical cord blood and perifheral blood CD34(+) hematopoietic stem cells. Exp. Hematol., 28(11):1297-305, 2000.

Gimble, J. M.; Katz, A. J. \& Bunnell, B. A. Adipose-derived stem cells for regenerative medicine. Circ. Res., 100:1249-60, 2007.

Harman, R.; Cowles, B.; Orava, C.; et al. A retrospective review of 66 cases of tendon injury in the equine treated with adipose derived stem and regenerative cell therapy. Vet. Stem internal data, 2006.

Herther, D. J. Enhanced suspensory ligament healing in 100 horses by stem cells and other bone marrow components. AAEP Proceedings, 47:319-21, 2001.

Koch, T. G.; Heerkens, T.; Thomsen, P. D. \& Betts, D. H. Isolation of mesenchymal stem cells from equine umbilical cord blood. BMC Biotechnol., 30:7-26, 2007. 
Koerner, J.; Nesic, D.; Romero, J. D.; Brehm, W.; Mainil-Varlet, P \& Grogan, S. P. Equine peripheral blood-derived progenitors in comparison to bone marrow-derived mesenchymal stem cells. Stem Cells, 24:1613-9, 2006.

Leeb, C.; Jurga, M.; McGuckin, C.; Moriggl, R. \& Kenner, L. Promising new sources for pluripotent stem cells. Stem Cell Rev., 6:15-26, 2010.

Litzke, L. E.; Wagner, E.; Baumgaertner, W.; Hetzel, U.; Josimovic'́ Alasevic', O. \& Libera, J. Repair of extensive articular cartilage defects in horses by autologous chondrocyte transplantation. Ann. Biomed. Eng., 32:57-69, 2004.

Maherali, N. \& Hochedlinger, K. Guidelines and techniques for the generation of induced pluripotent stem cells. Cell Stem Cell, 3(6):595-605, 2008.

Martin, D. R.; Cox, N. R.; Hathcock, T. L.; Niemeyer, G. P. \& Baker, H. J. Isolation and characterization of multipotential mesenchymal stem cells from feline bone marrow. Exp. Hematol., 3:879-86, 2002.

Meruane, M. \& Rojas, M. Células troncales derivadas del tejido adiposo. Int. J. Morphol., 28(3):879-89, 2010.

Meruane, MA; Rojas, M; Marcelain, K. Use of adipose tissue-derived stem cells within a dermal substitute improves skin regeneration by increasing neoangiogenesis and collagen synthesis. Plast. Reconstr. Surg., 30(1):53-63, 2012.

McGuckin, C. P.; Pearce, D.; Forraz, N.; Tooze, J. A.; Watt, S. M. \& Pettengell, R. Multiparametric analysis of immature cell populations in umbilical cord blood and bone marrow. Eur. J. Haematol., 71(5):341-50, 2003.

Mitalipova, M. M.; Rao, R. R.; Hoyer, D. M.; Johnson, J. A.; Meisner, L. F.; Jones, K. L.; Dalton, S. \& Stice, S. L. Preserving the genetic integrity of human embryonic sterm cells.Nat. Biotechnol., 23:1920, 2005.

Muñoz, L \& Concha, M. Guía de Seminarios, Unidad Biología del Desarrollo. Bases Celulares, Genéticas y del Desarrollo Ontogénico. Curso Obstetricia y Puericultura. Fac Medicina, Universidad de Chile 2011.

Puissant, B.; Barreau, C.; Bourin, P.; Clavel, C.; Corre, J.; Bousquet, C.; Taureau, C.; Cousin, B.; Abbal, M.; Laharrague, P.; Penicaud, L.; Casteilla, L. \& Blancher, A. Immunomodulatory effect of human adipose tissue-derived adult stem cells: comparison with bone marrow mesenchymal stem cells. Br. J. Haematol., 129:118-29, 2005.

Rehman, J.; Traktuev, D.; Li, J.; Merfeld-Clauss, S.; Temm-Grove, C. J.; Bovenkerk, J. E.; Pell, C. L.; Johnstone, B. H.; Considine, R. V. $\&$ March, K. L. Secretion of angiogenic and antiapoptotic factors by human adipose stromal cells. Circulation, 109:1292-8, 2004.

Rojas, M. A.; Vignon, X.; Montenegro, M. A.; del Sol, M.; BustosObregón, E. \& Fléchon, J. Caracterización, aislamiento y cultivo de células germinales primordiales de conejo. Rev. Chil. Anat., 19(2):213-20, 2001.
Rojas, M; Venegas, F; Montiel, E; Servely, J; Vignon, X \& Guillomot, M. Attempts at Applying Cloning to the Conservation of Species in Danger of Extinction. Int. J. Morphol., 23(4):329-336, 2005.

Rojas, M.; Castro, R.; Alvarez, R.; Guillomot, M. \& Venegas, F. Impacto de la biotecnología reproductiva en la conservación de los animales en riesgo de extinción. Revista TecnoVet., 3:9-15. 2006.

Smith, R.K; Korda, M; Blunn, G.W. \& Goodship, A.E. Isolation and implantation of autologous equine mesenchymal stem cells from bone marrow into the superficial digital flexor tendon as a potential novel treatment. Equine Vet. J. 35(1): 99-102. 2003.

Takahashi, K. \& Yamanaka, S. Induction of pluripotent stem cells from mouse embryonic and adult fibroblast cultures by defined factors. Cell, 126:663-76, 2006.

Thomson, J. A.; Itskovitz-Eldor, J.; Shapiro, S.; Waknitz, M.; Swiergiel, J.; Marshall, V. \& Jones, J. Embryonic stem cells line derived from human blastocyst. Science, 282:1145-7, 1998.

Uccelli, A.; Pistoia, V. \& Moretta, L. Mesenchymal stem cells: a new strategy for inmunosuppression? Trends Inmunol., 28(5):221-6, 2007.

Vidal, M.A., Kilroy, G.E; Lopez, M.J; Johnson, J.R; Moore R.M. \& Gimble J.M. Characterization of equine adipose tissue-derived stromal cells: Adipogenic and osteogenic capacity and comparison with bone marrow-derived mesenchymal stromal cells. Vet. Surg, 36(7):613-22, 2007.

Wagner, J. E. \& Gluckman, E. Umbilical cord blood transplantation: the first 20 years. Semin. Hematol., 47(1):3-12, 2010.

Wang, M.; Crisostomo, P.; Herring, C.; Meldrum, K. K. \& Meldrum, D. R. Human progenitor cells from bone marrow or adipose tissue produce VEGF, HGF and IGF-1 in response to TNF by a p38 mitogen activated protein kinase dependent mechanism. Am. $J$. Physiol. Regul. Integr. Comp. Physiol., 291:880-4, 2006.

Young, H. E.; Mancini, M. L.; Wright, R. P.; Smith, J. C.; Black, A. C. Jr.; Reagan, C. R. \& Lucas, P. A. Mesenchymal stem cells reside within the connective tissues of many organs. Dev. Dyn., 202:13744, 1995.

Zuk, P. A.; Zhu, M.; Mizumo, H.; Huang, J.; Futrell, J. W.; Katz, A. J.; Benhaim, P.; Lorenz, H. P. \& Hedrick, M. H. Multilineage cells from human adipose tissue: implications for cell-based therapies. Tissue Eng., 7:211-28, 2001.

Dirección para correspondencia:

Dra. Mariana Rojas R.

Laboratorio de Embriología Comparada

Programa de Anatomía y Biología del Desarrollo

Facultad de Medicina, ICBM

Universidad de Chile

Santiago

CHILE

E-mail: dramrojas@hotmail.com

Recibido : 22-07-2012

Aceptado: 18-08-2012 